\title{
Analisis Sistem Kerja untuk Meningkatkan Produktivitas Pegawai Negeri Sipil dengan Pendekatan Macroergonomic Analysis and Design
}

\author{
Delvieri Salsa Bella Putri' ${ }^{1}$, Wahyudin ${ }^{2}$, Hamdani ${ }^{3}$ \\ ${ }^{1,2,3}$ Program Studi Teknik Industri, Fakultas Teknik, Universitas Singaperbangsa Karawang \\ *Koresponden email: delvieri21@gmail.com
}

Diterima: 15 Oktober 2021

Disetujui: 2 November 2021

\begin{abstract}
The productivity of a job is influenced by many things, one of which is the work system. To get optimal productivity, it is necessary to design a good work system. A good work system at least provides security and comfort to workers when carrying out their work. Thus, workers can do work more actively and achieve the targets that have been set previously. This research is applied in the Community and Village Empowerment Service (DPMD) especially in the general and staffing sub-sections. The purpose of this study is to identify the work system applied to the DPMD, and evaluate the work system in order to get better conditions to increase productivity. The method of data analysis is using macroergonomy approach namely MEAD which is used in analyzing and evaluating work systems with structured and systematic steps. From the results obtained, it is known that the work system implemented by the DPMD has been running effectively and efficiently in accordance with the established vision and mission. While the factors that affect productivity are the physical environment, work equipment, working conditions, and organizational systems. From the calculation of \% HR Reserve and Cardiovascular Load (\% CVL) the value is $56.34 \%$ while the rest time is -0.083 . From these results, it is known that the rest time given is sufficient and there is no need for additional rest periods.
\end{abstract}

Keywords: work system, productivity, DPMD, optimal, MEAD

\begin{abstract}
Abstrak
Produktivitas suatu pekerjaan dipengaruhi oleh banyak hal, salah satunya adalah sistem kerja. Untuk mendapatkan produktivitas yang optimal, maka perlu merancang suatu sistem kerja yang baik. Sistem kerja yang baik setidaknya memberikan keamanan dan kenyamanan pada pekerja saat melaksanakan pekerjaannya. Dengan demikian pekerja dapat melakukan pekerjaan dengan lebih aktif dan mencapai target yang telah ditetapkan sebelumnya. Penelitian ini diterapkan di Dinas Pemberdayaan Masyarakat dan Desa (DPMD) khususnya pada sub bagian umum dan kepegawaian. Tujuan penelitian ini yaitu mengidentifikasi sistem kerja yang diterapkan pada DPMD, serta mengevaluasi sistem kerja tersebut guna mendapatkan kondisi yang lebih baik untuk dapat meningkatkan produktivitas. Metode analisis data yaitu dengan menggunakan pendekatan makroergonomi yaitu MEAD yang digunakan dalam menganalisis dan evaluasi sistem kerja dengan langkah terstruktur dan sistematis. Dari hasil yang didapatkan, diketahui sistem kerja yang diterapkan oleh DPMD sudah berjalan efektif dan efisien sesuai dengan visi dan misi yang sudah ditetapkan. Sedangkan faktor-faktor yang mempengaruhi produktivitas yaitu ada lingkungan fisik, peralatan kerja, kondisi pekerjaan, dan sistem organisasi. Dari perhitungan \% HR Reserve dan Cardiovaskuler Load (\% CVL) didapatkan nilai 56,34\% sedangkan waktu istirahat $-0,083$. Berdasarkan hasil tersebut diketahui bahwa waktu istirahat yang diberikan sudah cukup dan tidak perlu adanya penambahan waktu istirahat.
\end{abstract}

Kata Kunci: sistem kerja, produktivitas, DPMD, optimal, MEAD

\section{Pendahuluan}

Kondisi seperti saat ini persaingan industri terjadi bukan hanya dalam negeri melainkan di seluruh dunia. Era persaingan ini disebabkan salah satunya adalah karena permintaan konsumen yang semakin tinggi. Sehingga setiap perusahaan harus mampu mengembangkan pengetahuan dan teknologinya guna memenuhi kebutuhan konsumen agar tetap dapat bersaing dengan perusahaan lain. Berkembangnya ilmu pengetahuan dan teknologi menciptakan tingkat kompleksitas yang lebih tinggi dalam sistem kerja [1]. Sistem kerja adalah urutan dan prosedur suatu pekerjaan yang kemudian akan membentuk suatu pola yang tetap dalam pelaksanaan pekerjaan tersebut. Kompleksitas sistem kerja yang tinggi menyebabkan kumpulan 
pekerjaan dapat mengidentifikasi sistem kerjanya untuk mencapai hasil yang optimal. Dalam menganalisis sistem kerja dapat menggunakan beberapa cara, salah satunya dengan ergonomi makro. Menurut pendapat yang dikemukakan oleh ref. [2] objek kajian dalam ergonomi makro meliputi motivasi pekerja, struktur organisasi, serta interaksi yang terjadi di dalam organisasi tersebut [1]. Beberapa komponen yang ada pada sistem kerja diantaranya pekerjaan, peralatan, masalah lingkungan dan yang lainnya [3]. Dalam menjalankan pekerjaannya, setiap organisasi memiliki ciri khas dan budaya organisasi yang khas, baik itu organisasi pendidikan, pemerintahan, maupun perusahaan [4]. Adanya perkembangan teknologi serta persaingan internasional dalam segala aspek, membuat analisis sistem kerja yang semula berskala mikro menjadi skala makro. Hal ini dikarenakan analisis skala mikro sulit ketika dalam praktik bahkan terjadi kegagalan dalam proses pemecahan masalah, sehingga diperlukan pendekatan yang holistik [5]. Pendekatan secara menyeluruh dan tersusun sangat diperlukan dalam rangka mencapai tujuan suatu pekerjaan, yaitu dapat dilakukan dengan aman dan nyaman. Tidak dapat dipungkiri, rasa nyaman Ketika melakukan pekerjaan dapat mempengaruhi hasil pekerjaan dan produktivitas pekerjaan itu sendiri.

Dinas Pemberdayaan Desa dan Masyarakat (DPMD) merupakan dinas pemerintah daerah yang mengatur dana anggaran, kegiatan desa, dan inventarisasi aset data untuk setiap desa. Dalam penelitian ini ditempatkan pada Sub bagian Departemen Umum dan Kepegawaian yang tugasnya mengelola inventarisasi barang di kantor, dan menyusun kebutuhan alat tulis kantor, memverifikasi surat masuk dan keluar, dan membuat laporan berkala kepada pimpinan. Sebuah permasalahan yang terjadi pada DPMD adalah pada produktivitas kerja yang dilakukan oleh pegawai. Karena itu, perlu dilakukan proses identifikasi untuk mengetahui letak pokok permasalahan yang ada yaitu dengan penerapan Macroergonomic Analysis and Design (MEAD) dalam rangka meningkatkan produktivitas [6]. Perbaikan pada lingkungan kerja, alat kerja, serta postur kerja merupakan bagian dari perbaikan pada sistem kerja yang berskala makro [7]. Metode MEAD dapat digunakan untuk menganalisis sistem kerja dengan tujuan untuk meningkatkan produktivitas yang ada [8]. Penelitian ini bertujuan untuk mengidentifikasi sistem kerja yang diterapkan pada DPMD dan mengevaluasi sistem kerja untuk memberikan saran perbaikan yang dapat dilakukan. Sistem kerja adalah suatu pelaksanaan proses kerja secara bersama dengan ciri-ciri tertentu [9]. Sistem kerja yang baik diperlukan oleh perusahaan sebagai penunjang untuk peningkatan produktivitas pekerjaan [10].

Kemudian diambil beberapa penelitian dengan maksud sebagai acuan dan juga penentuan posisi penelitian. Penelitian yang dilakukan [11] Analisis MEAD digunakan dalam desain filter air kedelai. Menurut ref. [12], analisis MEAD digunakan untuk mengetahui hasil produktivitas pegawai setelah pengadaan mesin baru. Ref. [13] juga melaporkan analisis MEAD digunakan untuk mengevaluasi kerja operator untuk meningkatkan sistem kerja dan pelayanan. Penelitian dilakukan ref. [14], analisis MEAD digunakan untuk merancang yang bertujuan untuk menciptakan cara kerja yang nyaman dan bebas dari keluhan. Penelitian dilakukan ref. [15], analisis MEAD digunakan untuk merancang printer dan mesin pres tahu untuk mendapatkan hasil kerja yang optimal. Analisis kesenjangan antara penelitian terdahulu dengan penelitian saat ini adalah untuk mendapatkan posisi penelitian saat ini.

Pada penelitian sebelumnya diketahui MEAD digunakan untuk mengidentifikasi dan menganalisis sistem kerja dan peralatan kerja saja. Sedangkan pada penelitian saat ini dilakukan langkah lebih lanjut. Setelah penggunaan analisis MEAD untuk mendapatkan evaluasi sistem kerja, kemudian dianalisis menggunakan $5 \mathrm{~W}+1 \mathrm{H}$ untuk mengidentifikasi langkah pasti untuk memperbaiki berdasarkan indikator permasalahan yang ada. Dengan demikian hasil analisis dan langkah perbaikan yang akan dilakukan dapat lebih sesuai dengan kondisi nyata dilapangan. Tujuan penelitian ini yaitu mengidentifikasi sistem kerja yang diterapkan pada DPMD, serta mengevaluasi sistem kerja tersebut guna mendapatkan kondisi yang lebih baik untuk dapat meningkatkan produktivitas.

\section{Metode Penelitian}

Metodologi dalam penelitian ini digambarkan dengan menggunakan diagram alir seperti yang terdapat pada Gambar 1.

a. Mulai, pada tahap ini merupakan penandaan sejak dimulainya penelitian ini.

b. Studi Pendahuluan dimaksudkan untuk mencari informasi yang berkaitan dengan penelitian seperti studi literatur dan studi lapangan untuk mempelajari korelasi antara teori dan kondisi lapangan. 


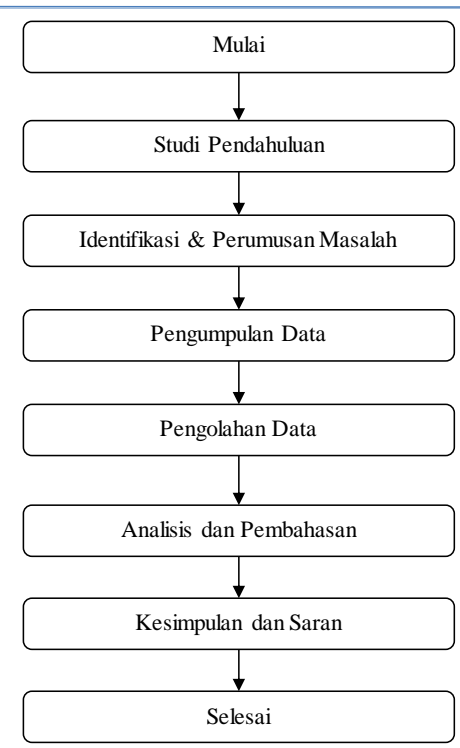

Gambar 1. Alur Penelitian

Sumber: Pengolahan data peneliti (2021)

c. Identifikasi dan Perumusan masalah, yaitu mengidentifikasi dan merumuskan masalah yang terjadi pada objek penelitian yaitu berupa potensi kecelakaan kerja.

d. Pengumpulan Data, dimana data yang digunakan dalam penelitian ini adalah data primer. Prosedur pengumpulan data dalam penelitian ini adalah dengan melakukan wawancara dan observasi untuk mendapatkan data yang dibutuhkan.

e. Pengolahan Data, pada tahap ini dilakukan dengan menerapkan metode MEAD untuk mengevaluasi sistem kerja yang sedang berjalan pada objek penelitian.

f. Analisis dan Pembahasan, yaitu menganalisis hasil yang diperoleh pada tahap pengolahan data. Kemudian dibahas tujuan dari hasil tersebut untuk kemudian diterapkan pada situasi yang sebenarnya. Setelah didapatkan hasil seperti konsumsi energi dan kebutuhan waktu istirahat pada metode MEAD. Selanjutnya dilanjutkan dengan menggunakan analisis Kaizen $5 \mathrm{~W}+1 \mathrm{H}$. Hal ini dilakukan agar proses perbaikan yang akan dilakukan lebih terstruktur dan sesuai dengan kondisi nyata di lapangan. Analisis ini didasarkan pada pertanyaan-pertanyaan dari penyebab permasalahan, tempat terjadinya, hingga bagaimana memperbaikinya.

g. Kesimpulan dan Saran, yaitu menarik kesimpulan ketika hasil yang diinginkan telah diperoleh. Selain itu, memberikan saran bagi perusahaan dan penelitian selanjutnya untuk dapat menutupi kekurangan dari penelitian ini.

h. Selesai, itu menandai selesainya penelitian

\section{Hasil dan Pembahasan}

Pada penelitian ini berfokus pada analisis sistem kerja dan perbaikan yang dapat dilakukan pada DPMD. Digunakan data pada penelitian ini berupa denyut nadi pegawai DPMD ketika melakukan pekerjaan dan ketika beristirahat. Berikut rekapitulasi data denyut pegawai pada DPMD Karawang yang terdapat pada Tabel 1.

Tabel 1. Rekapitulasi data denyut nadi

\begin{tabular}{|c|c|c|c|c|c|c|c|}
\hline \multirow[t]{2}{*}{ No. } & \multirow[t]{2}{*}{ Nama Responden } & \multirow{2}{*}{$\begin{array}{l}\text { Jenis } \\
\text { Kelamin }\end{array}$} & \multirow{2}{*}{$\begin{array}{c}\text { Usia } \\
\text { (Tahun) }\end{array}$} & \multirow{2}{*}{$\begin{array}{l}\text { Denyut Nadi } \\
\text { Istirahat } \\
\text { (Detik) }\end{array}$} & \multicolumn{2}{|c|}{$\begin{array}{c}\text { Denyut Nadi Kerja } \\
\text { (Detik) }\end{array}$} & \multirow{2}{*}{$\begin{array}{l}\text { Rata-rata Denyut } \\
\text { Nadi Kerja (Detik) }\end{array}$} \\
\hline & & & & & I & II & \\
\hline 1. & Dedi Karyadi & Laki-laki & 57 & 79 & 112 & 93 & 102,5 \\
\hline 2. & Okky & Laki-laki & 54 & 81 & 114 & 99 & 106,5 \\
\hline 3. & Bima & Laki-laki & 25 & 79 & 126 & 110 & 118 \\
\hline 4. & Komarudin & Laki-laki & 54 & 63 & 109 & 92 & 100,5 \\
\hline 5. & Marwan & Laki-laki & 53 & 73 & 113 & 98 & 105,5 \\
\hline 6. & Tata & Laki-laki & 54 & 82 & 110 & 97 & 103,5 \\
\hline
\end{tabular}




\begin{tabular}{|c|c|c|c|c|c|c|c|}
\hline \multirow{2}{*}{ No. } & \multirow[t]{2}{*}{ Nama Responden } & \multirow{2}{*}{$\begin{array}{c}\text { Jenis } \\
\text { Kelamin }\end{array}$} & \multirow{2}{*}{$\begin{array}{c}\text { Usia } \\
\text { (Tahun) }\end{array}$} & \multirow{2}{*}{$\begin{array}{l}\text { Denyut Nadi } \\
\text { Istirahat } \\
\text { (Detik) }\end{array}$} & \multicolumn{2}{|c|}{$\begin{array}{c}\text { Denyut Nadi Kerja } \\
\text { (Detik) }\end{array}$} & \multirow{2}{*}{$\begin{array}{l}\text { Rata-rata Denyut } \\
\text { Nadi Kerja (Detik) }\end{array}$} \\
\hline & & & & & $\mathrm{I}$ & II & \\
\hline 7. & Peppy & Laki-laki & 37 & 60 & 124 & 112 & 118 \\
\hline 8. & Mad Yusuf & Laki-laki & 43 & 74 & 116 & 98 & 107 \\
\hline 9. & Agus & Laki-laki & 48 & 72 & 109 & 94 & 101,5 \\
\hline 10. & Andry & Laki-laki & 42 & 79 & 112 & 96 & 104 \\
\hline
\end{tabular}

Sumber: Pengolahan data peneliti (2021)

Pengukuran denyut nadi karyawan pada Tabel 1 diukur menggunakan aplikasi berbasis smartphone yaitu "Cardiograph". Dari data tersebut dilakukan analisis dan pengolahan data mengenai sistem kerja untuk meningkatkan produktivitas karyawan. Pendekatan Analisis dan Desain Makroergonomi digunakan dengan beberapa tahapan sebagai berikut:

\section{Mengidentifikasi Jenis Sistem Operasi yang Bekerja}

Tahap paling awal dalam menganalisis suatu sistem kerja adalah dengan mengetahui komposisi pekerjaan yang ada didalam objek penelitian. Hal ini digunakan sebagai dasar sebelum menentukan dan melakukan analisis pada tahap-tahap selanjutnya. Pada tahap ini, identifikasi sistem kerja yang terdapat dalam DPMD dilakukan pada Sub Bidang Umum dan Kepegawaian. Seperti pada Tabel 2.

Tabel 2. Tipe sistem operasi kerja

\begin{tabular}{clccc}
\hline No. & \multicolumn{1}{c}{ Rincian Tugas/Kegiatan } & Satuan & Waktu & Peralatan \\
\hline 1. $\begin{array}{l}\text { Membuat perencanaan dan Menyusun } \\
\text { program kerja Sub Bagian Umum dan } \\
\text { Kepegawaian }\end{array}$ & Dokumen & 30 menit & $\begin{array}{c}\text { Tupoksi dan kebijakan } \\
\text { pimpinan }\end{array}$ \\
2. $\begin{array}{l}\text { Memfasilitasi pembinaan tertib administrasi } \\
\text { pengelolaan barang di lingkungan Dinas } \\
\text { Menyusun dan mengelola rencana } \\
\text { kebutuhan dan pengembangan pegawai }\end{array}$ & Dokumen & Dokumen menit & 20 menit & Program kerja unit \\
3. & Program kerja unit \\
\hline
\end{tabular}

Sumber: Pengolahan data peneliti (2021)

\section{Menentukan Unit Operasional dan Proses Kerja}

Pelaksanaan pekerjaan memerlukan alat penunjang untuk membantu melaksanakan pekerjaan tersebut. Proses kerja yang dilakukan di DPMD hanya berkaitan dengan arsip dan dokumen sehingga untuk menyelesaikan proses kerja seorang pegawai hanya membutuhkan media peralatan kantor salah satunya adalah komputer. Berikut unit kerja atau peralatan kantor di DPMD ditunjukkan pada Tabel 3.

Tabel 3. Peralatan dan fasilitas kerja

\begin{tabular}{clc}
\hline No & \multicolumn{1}{c}{ Peralatan } & Jumlah Peralatan \\
\hline 1 & Komputer & 20 \\
2 & Meja Kerja & 45 \\
3 & Kursi Kerja & 45 \\
4 & Sofa & 4 \\
5 & Lemari & 60 \\
6 & Printer & 20 \\
\hline & & Sumber: Pengolahan data peneliti (2021)
\end{tabular}

\section{Mengidentifikasi Data Varian}

Sebelum dilanjutkan pada tahap selanjutnya maka perlu dirumuskan terkait dengan fokus permasalahan yang terjadi. Perumusan masalah ini disebut dengan data varian yang nantinya akan dianalisis, diidentifikasi, dan dievaluasi untuk kemudian didapatkan alternatif perbaikannya. Permasalahan yang terjadi pada DPMD dapat dilakukan identifikasi varian data untuk memudahkan dalam menganalisis dan memecahkan masalah tersebut. Varian data dalam penelitian ini didapatkan melalui wawancara dengan beberapa pegawai di DPMD, bertujuan untuk mendapatkan data yang valid dan lebih detail. Berikut adalah hasil varians data dari wawancara yang telah dilakukan, yang ditunjukkan pada Tabel 4. 
Tabel 4. Hasil identifikasi varian data

\begin{tabular}{cl}
\hline Faktor Varian & \multicolumn{1}{c}{ Varian } \\
\hline \multirow{2}{*}{ Lingkungan fisik } & $\begin{array}{l}\text { Penataan ruangan yang tidak efektif } \\
\text { Penataan meja dan kursi kerja tidak sesuai } \\
\text { Kebersihan toilet dan mushola belum nyaman }\end{array}$ \\
Peralatan kerja & $\begin{array}{l}\text { Komputer melambat karena faktor penggunaan } \\
\text { Kondisi kerja }\end{array}$ \\
& $\begin{array}{l}\text { Pekerja memiliki beban kerja yang ringan } \\
\text { Kurangnya perhatian dari pimpinan }\end{array}$ \\
Sistem Organisasi & $\begin{array}{l}\text { Tidak ada penghargaan yang diberikan pimpinan kepada } \\
\text { karyawan }\end{array}$ \\
\hline & Sumber: Pengolahan data peneliti (2021)
\end{tabular}

\section{Membuat Matriks Variansi}

Setelah didapatkan varians pada tahap sebelumnya, selanjutnya dilakukan analisis untuk mengetahui hubungan antara masing-masing varian tersebut. Analisis ini ditujukan untuk mengidentifikasi apakah terdapat pengaruh antara satu varian dengan varian yang lain. Berikut adalah matriks varians seperti yang ditunjukkan pada Tabel 5. 
Tabel 5. Matriks Variansi

\begin{tabular}{|c|c|c|c|c|c|c|c|c|c|c|}
\hline Faktor Varian & Varian & 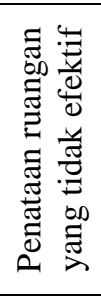 & 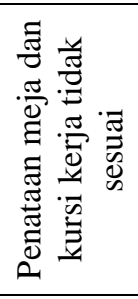 & 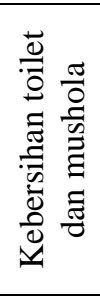 & 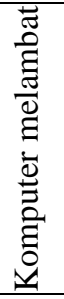 & 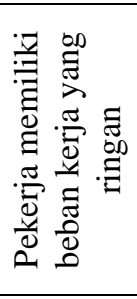 & 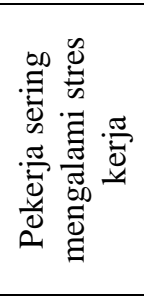 & 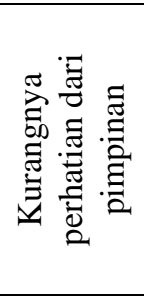 & 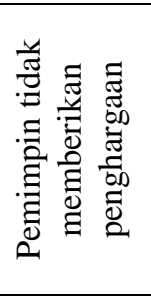 & $\frac{\text { 売 }}{\Xi}$ \\
\hline \multirow{3}{*}{$\begin{array}{l}\text { Lingkungan } \\
\quad \text { fisik }\end{array}$} & Penataan ruangan yang tidak efektif & & $\mathrm{x}$ & & & & $\mathrm{x}$ & $\mathrm{x}$ & & 3 \\
\hline & Penataan meja dan kursi kerja tidak sesuai & $\mathrm{x}$ & & & & & & $\mathrm{x}$ & & 2 \\
\hline & $\begin{array}{l}\text { Kebersihan toilet dan mushola belum } \\
\text { nyaman }\end{array}$ & & & & & & & $\mathrm{x}$ & & 1 \\
\hline Peralatan kerja & $\begin{array}{l}\text { Komputer melambat karena faktor } \\
\text { penggunaan }\end{array}$ & & & & & & $\mathrm{x}$ & $\mathrm{x}$ & & 2 \\
\hline \multirow{2}{*}{ Kondisi kerja } & Pekerja memiliki beban kerja yang ringan & & & & & & & & $\mathrm{x}$ & 1 \\
\hline & Pekerja sering mengalami stres kerja & $\mathrm{x}$ & $\mathrm{x}$ & & $\mathrm{x}$ & & & & $\mathrm{x}$ & 4 \\
\hline \multirow{2}{*}{$\begin{array}{l}\text { Sistem } \\
\text { Organisasi }\end{array}$} & Kurangnya perhatian dari pimpinan & & & & $\mathrm{x}$ & $\mathrm{x}$ & & & & 2 \\
\hline & $\begin{array}{l}\text { Tidak ada penghargaan yang diberikan } \\
\text { pimpinan kepada karyawan }\end{array}$ & & & & & & $\mathrm{x}$ & & & 1 \\
\hline
\end{tabular}

Sumber: Pengolahan data peneliti (2021) 


\section{Tabel kontrol varian utama dengan jaringan peran}

Tahap selanjutnya adalah menentukan dan mengetahui pengendalian varian yang dimiliki dan juga peran atau tanggung jawab di DPMD. Hasilnya ditunjukkan pada Tabel 6.

Tabel 6. Hasil varian utama dengan jaringan peran

\begin{tabular}{|c|c|c|c|c|c|}
\hline No. & Varian kunci & Tempat & $\begin{array}{l}\text { Pihak yang } \\
\text { menangani }\end{array}$ & $\begin{array}{c}\text { Pihak yang } \\
\text { terlibat langsung }\end{array}$ & $\begin{array}{c}\text { Aktifitas } \\
\text { pendukung }\end{array}$ \\
\hline 1. & $\begin{array}{l}\text { Penataan ruangan } \\
\text { yang belum efektif }\end{array}$ & $\begin{array}{l}\text { Sub Bagian Umum dan } \\
\text { Kepegawaian }\end{array}$ & Pimpinan & Pekerja & - \\
\hline 2. & $\begin{array}{l}\text { Pekerja sering } \\
\text { mengalami stress } \\
\text { kerja }\end{array}$ & $\begin{array}{c}\text { Sub Bagian Umum dan } \\
\text { Kepegawaian }\end{array}$ & Pimpinan & Pekerja & - \\
\hline
\end{tabular}

\section{Mengalokasikan Fungsi dan Desain Bersama}

Tahap selanjutnya adalah merancang analisis perbaikan dengan fungsi alokasi berdasarkan tabel kendali varians yang kemudian diubah menjadi pohon tujuan. Hasilnya seperti yang ditunjukkan pada Gambar 2.

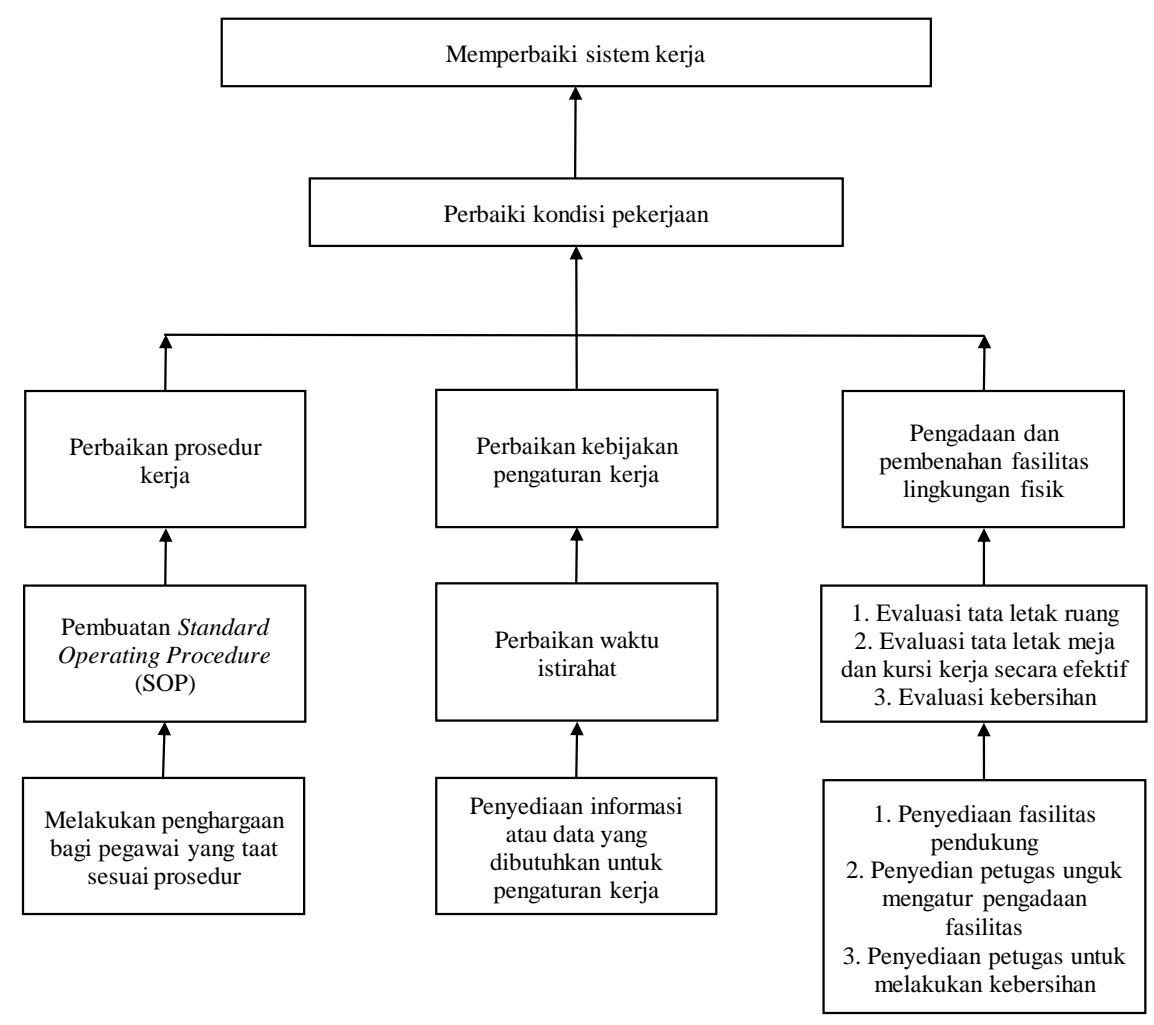

Gambar 2. Hasil pohon objektif alternatif

Sumber: Pengolahan data peneliti (2021)

\section{Analisis Peran dan Tanggung Jawab}

Untuk mendapatkan alternatif terbaik, maka dilakukan penilaian dan pembobotan dari setiap alternatif. Berikut adalah hasil pembobotan seperti terlihat pada Tabel 7.

Tabel 7. Pemberian bobot alternatif kunci

\begin{tabular}{lccccc}
\hline \multicolumn{1}{c}{ Alternatif } & $\begin{array}{c}\text { Jangkauan } \\
\text { terhadap } \\
\text { organisasi }\end{array}$ & $\begin{array}{c}\text { Risiko yang akan } \\
\text { terjadi/kendala } \\
\text { dalam } \\
\text { keberhasilan }\end{array}$ & $\begin{array}{c}\text { Keuntungan } \\
\text { /keefektifan }\end{array}$ & $\begin{array}{c}\text { Pengaruh } \\
\text { terhadap } \\
\text { pengeluaran } \\
\text { biaya }\end{array}$ & $\begin{array}{c}\text { Total } \\
\text { Bobot }\end{array}$ \\
\hline $\begin{array}{l}\text { Perbaikan prosedur } \\
\text { kerja }\end{array}$ & 4 & -2 & 6 & -2 & 6 \\
$\begin{array}{l}\text { Perbaikan kebijakan } \\
\text { pengaturan kerja }\end{array}$ & 3 & -3 & 4 & -2 & 2 \\
\hline
\end{tabular}




\begin{tabular}{|c|c|c|c|c|c|}
\hline Alternatif & $\begin{array}{c}\text { Jangkauan } \\
\text { terhadap } \\
\text { organisasi }\end{array}$ & $\begin{array}{c}\text { Risiko yang akan } \\
\text { terjadi/kendala } \\
\text { dalam } \\
\text { keberhasilan }\end{array}$ & $\begin{array}{l}\text { Keuntungan } \\
\text { /keefektifan }\end{array}$ & $\begin{array}{c}\text { Pengaruh } \\
\text { terhadap } \\
\text { pengeluaran } \\
\text { biaya } \\
\end{array}$ & $\begin{array}{c}\text { Total } \\
\text { Bobot }\end{array}$ \\
\hline $\begin{array}{l}\text { Pengadaan dan } \\
\text { pembenahan fasilitas } \\
\text { fisik }\end{array}$ & 4 & -2 & 5 & -4 & 3 \\
\hline
\end{tabular}

Sumber: Pengolahan data peneliti (2021)

\section{Merancang Subsistem Pendukung}

Tahap kedelapan ini dimaksudkan sebagai rencana perbaikan sekaligus untuk menentukan kebutuhan waktu istirahat karyawan. Hal ini agar sistem kerja yang terjadi bisa lebih baik lagi, oleh karena itu diukur dan dihitung denyut nadi para pekerja, dan regangan Cardiovasculair (\%CVL). Berikut hasil pengukuran ketiga indikator tersebut seperti terlihat pada Tabel 8.

Tabel 8. Data waktu 10 denyut nadi pekerja

\begin{tabular}{cllcccc}
\hline \multirow{2}{*}{ No. } & $\begin{array}{c}\text { Nama } \\
\text { Responden }\end{array}$ & $\begin{array}{c}\text { Jenis } \\
\text { Kelamin }\end{array}$ & $\begin{array}{c}\text { Usia } \\
\text { (Tahun) }\end{array}$ & $\begin{array}{c}\text { Denyut Nadi } \\
\text { Istirahat (Detik) }\end{array}$ & $\begin{array}{c}\text { Denyut Nadi } \\
\text { Kerja (Detik) }\end{array}$ & $\begin{array}{c}\text { Denyut Nadi } \\
\text { Maksimal (Detik) }\end{array}$ \\
\hline 1. & Dedi Karyadi & Laki-laki & 57 & 79 & 102,5 & 130,4 \\
2. & Okky & Laki-laki & 54 & 81 & 106,5 & 132,8 \\
3. & Bima & Laki-laki & 25 & 79 & 118 & 156 \\
4. & Komarudin & Laki-laki & 54 & 63 & 100,5 & 132,8 \\
5. & Marwan & Laki-laki & 53 & 83 & 105,5 & 133,6 \\
6. & Tata & Laki-laki & 54 & 85 & 103,5 & 132,8 \\
7. & Peppy & Laki-laki & 37 & 60 & 118 & 146,4 \\
8. & Mad Yusuf & Laki-laki & 43 & 74 & 107 & 141,6 \\
9. & Agus & Laki-laki & 48 & 72 & 101,5 & 137,6 \\
10. & Andry & Laki-laki & 45 & 79 & 104 & 143,5 \\
\hline \multicolumn{7}{c}{ Sata-rata } \\
\hline \multicolumn{7}{c}{ Sumber: Pengolahan data peneliti (2021) } \\
\end{tabular}

Berdasarkan hasil pengukuran denyut nadi diatas, kemudian dilakukan beberapa indikator pengukuran untuk menentukan lama waktu istirahat pegawai. Hal ini bertujuan untuk mengevaluasi waktu istirahat yang telah dilaksanakan apakah perlu penambahan, tetap, atau pengurangan. Didapatkan hasil sebagai berikut:

a. \% HR Reserve $=50,34 \%$

b. Beban kardiovaskular $(\% \mathrm{CVL})=50,34 \%$

c. Konsumsi Energi:

$\mathrm{Et}=4,73 \mathrm{kkal} /$ menit

$\mathrm{Ei}=2,7 \mathrm{kkal} / \mathrm{menit}$

$\mathrm{K}=E t-E i$

$$
=4,73-2,7=2,03 \mathrm{kkal} / \text { menit }
$$

d. Perhitungan Waktu Istirahat

$\mathrm{W}=4,73 \mathrm{kkal} / \mathrm{menit}$

$\mathrm{T}=480$ menit/hari kerja

$\begin{array}{ll}\text { Batas wanita } & =4 \mathrm{kkal} / \text { menit } \\ \text { Batas pria } & =5 \mathrm{kkal} / \text { menit } \\ \text { Metabolisme Basal } & =1,5 \mathrm{kkal} / \text { menit }\end{array}$

Perhitungan waktu istirahat $=-0,083$ menit

Pada hasil perhitungan diatas dapat diketahui waktu istirahat memiliki hasil $-0,083$ menit sehingga hasilnya minus sehingga tidak perlu tambahan waktu istirahat. Namun, perhitungan tersebut berarti ada kekurangan produktivitas yang dilakukan oleh pegawai negeri sipil di DPMD.

\section{Implementasi, Iterasi, dan Perbaikan}

Selanjutnya adalah tahap terakhir yang dimaksudkan sebagai implementasi perbaikan yang telah dirumuskan pada alternatif yang dipilih. Implementasi ini berupa perbaikan dengan mengukur denyut nadi karyawan yang akan digunakan untuk menentukan waktu istirahat karyawan. Hal ini dimaksudkan untuk membantu mengurangi tingkat kelelahan yang dialami oleh pegawai. Dari hasil perhitungan denyut nadi didapatkan hasil perhitungan \%CVL yang diperoleh sebesar 50,34\% dan konsumsi energi sebesar 
2,03 kkal/menit, sehingga beban kerja dapat dimasukkan ke dalam kategori sedang dan tidak ada perlu melakukan perbaikan selama istirahat karyawan. Untuk membuat perbaikan kecil dan sederhana namun berkelanjutan, analisis Kaizen $5 \mathrm{~W}+1 \mathrm{H}$ akan digunakan. Analisis ini digunakan untuk mengidentifikasi kesalahan yang terjadi dan penyebabnya serta mengidentifikasi cara perbaikan yang dapat dilakukan. Hasil analisis $5 \mathrm{~W}+1 \mathrm{H}$ seperti terlihat pada Tabel 9.

Tabel 9. Hasil analisis $5 \mathrm{~W}+1 \mathrm{H}$

\begin{tabular}{|c|c|c|c|c|c|}
\hline $\begin{array}{l}\text { Kesalahan apa } \\
\text { (What })\end{array}$ & $\begin{array}{c}\text { Waktu terjadinya } \\
\text { (When })\end{array}$ & $\begin{array}{l}\text { Tempat } \\
\text { terjadi } \\
\text { (Where) }\end{array}$ & $\begin{array}{c}\text { Penyebabnya } \\
\text { (Why) }\end{array}$ & $\begin{array}{l}\text { Penanggung } \\
\text { jawab (Who) }\end{array}$ & $\begin{array}{c}\text { Cara perbaikan } \\
(\text { How })\end{array}$ \\
\hline $\begin{array}{l}\text { Pekerjaan yang } \\
\text { saling } \\
\text { menunggu }\end{array}$ & $\begin{array}{l}\text { Saat } \\
\text { berlangsungnya } \\
\text { pekerjaan }\end{array}$ & $\begin{array}{l}\text { Sub bagian } \\
\text { umum dan } \\
\text { kepegawaian }\end{array}$ & $\begin{array}{l}\text { Terbatasnya } \\
\text { fasilitas yang } \\
\text { disediakan } \\
\text { untuk } \\
\text { melakukan } \\
\text { pekerjaan }\end{array}$ & $\begin{array}{l}\text { Pegawai sub } \\
\text { bagian umum } \\
\text { dan } \\
\text { kepegawaian }\end{array}$ & $\begin{array}{l}\text { Pengadaan } \\
\text { fasilitas yang } \\
\text { disesuaikan } \\
\text { dengan } \\
\text { kapasitas } \\
\text { pekerjaan }\end{array}$ \\
\hline $\begin{array}{l}\text { Hasil pekerjaan } \\
\text { yang tidak } \\
\text { sesuai }\end{array}$ & $\begin{array}{l}\text { Saat } \\
\text { berlangsungnya } \\
\text { pekerjaan }\end{array}$ & $\begin{array}{l}\text { Sub bagian } \\
\text { umum dan } \\
\text { kepegawaian }\end{array}$ & $\begin{array}{l}\text { Ketidaktelitian } \\
\text { pegawai karena } \\
\text { kondisi tubuh } \\
\text { yang mudah } \\
\text { lelah karena } \\
\text { faktor usia }\end{array}$ & $\begin{array}{l}\text { Pegawai sub } \\
\text { bagian umum } \\
\text { dan } \\
\text { kepegawaian }\end{array}$ & $\begin{array}{l}\text { Membuat } \\
\text { indikator } \\
\text { kinerja terkait } \\
\text { dengan } \\
\text { kualifikasi } \\
\text { pegawai dan } \\
\text { masa pensiun } \\
\text { atau tidak } \\
\text { dipekerjakan }\end{array}$ \\
\hline $\begin{array}{l}\text { Terlalu banyak } \\
\text { pegawai yang } \\
\text { menganggur }\end{array}$ & $\begin{array}{l}\text { Saat } \\
\text { berlangsungnya } \\
\text { pekerjaan }\end{array}$ & $\begin{array}{l}\text { Sub bagian } \\
\text { umum dan } \\
\text { kepegawaian }\end{array}$ & $\begin{array}{l}\text { Terlalu banyak } \\
\text { komposisi } \\
\text { pegawai }\end{array}$ & $\begin{array}{l}\text { Pegawai sub } \\
\text { bagian umum } \\
\text { dan } \\
\text { kepegawaian }\end{array}$ & $\begin{array}{l}\text { Penyesuaian } \\
\text { jumlah pegawai } \\
\text { yang } \\
\text { disesuaikan } \\
\text { dengan } \\
\text { kapasitas } \\
\text { pekerjaan dari } \\
\text { IKU dapat } \\
\text { dirancang } \\
\text { kembali }\end{array}$ \\
\hline $\begin{array}{lr}\text { Kondisi } & \text { dan } \\
\text { waktu } & \text { kerja } \\
\text { yang } & \text { tidak } \\
\text { sesuai dengan } & \\
\text { ketetapan } & \end{array}$ & $\begin{array}{l}\text { Saat } \\
\text { berlangsungnya } \\
\text { pekerjaan }\end{array}$ & $\begin{array}{l}\text { Sub bagian } \\
\text { umum dan } \\
\text { kepegawaian }\end{array}$ & $\begin{array}{l}\text { Kurangnya } \\
\text { kedisiplinan } \\
\text { kerja pada } \\
\text { pegawai DPMD }\end{array}$ & $\begin{array}{l}\text { Pegawai sub } \\
\text { bagian umum } \\
\text { dan } \\
\text { kepegawaian }\end{array}$ & $\begin{array}{l}\text { Merancang } \\
\text { SOP dan juga } \\
\text { sistem reward } \\
\text { dan punishment } \\
\text { terhadap } \\
\text { kualitas kerja } \\
\text { dari setiap } \\
\text { pegawai }\end{array}$ \\
\hline
\end{tabular}

Berdasarkan analisis $5 \mathrm{~W}+1 \mathrm{H}$ tersebut diharapkan mampu menjadi indikator tertentu sebagai perbaikan secara kecil dan sederhana namun kontinu. Hal ini bertujuan agar proses pekerjaan dan hasil yang didapatkan dapat sesuai dengan yang diharapkan dan lebih mengefisiensikan sistem kerja yang ada. Dari hasil analisis $5 \mathrm{~W}+1 \mathrm{H}$ tersebut dapat diketahui kesalahan yang dapat menghambat proses kerja seperti pekerjaan yang saling menunggu, hasil pekerjaan tidak sesuai, pegawai banyak yang menganggur, hingga kondisi dan waktu kerja yang tidak sesuai. Dari beberapa penghambat tersebut pihak DPMD dapat melakukan beberapa alternatif tindakan untuk mencegah dan mengurangi kemungkinan terjadinya hal tersebut. Yaitu dengan pengadaan fasilitas, membuat indikator kerja yang tepat, penyesuaian jumlah pegawai, hingga pada perancangan dan evaluasi ulang terhadap SOP yang tersedia.

\section{Kesimpulan}

Berdasarkan analisis sistem lingkungan dan subsistem organisasi pada metode Macroergonomic Analysis and Design, sistem kerja yang dilakukan di DPMD sudah berjalan baik dan efektif serta efisien sesuai dengan visi dan misi yang sudah ditetapkan pada DPMD. Faktor-faktor yang mempengaruhi 
produktivitas pegawai di DPMD Kabupaten Karawang terdiri dari lingkungan fisik, peralatan kerja, kondisi pekerjaan, dan sistem organisasi. Dengan hasil perhitungan persentase HR Reserve dan Cardiovaskuler Load (\% CVL) sebesar 56,34\%. Sedangkan, hasil yang didapatkan pada perhitungan konsumsi energi yaitu sebesar 2,03 kkal/menit. Serta pada perhitungan waktu istirahat menghasilkan perhitungan minus sebesar 0,083 menit sehingga tidak diperlukan penambahan waktu istirahat.

\section{Referensi}

[1] H. Purnomo dan K. Ferdianto, "Desain sistem kerja pada pengrajin mendong dengan pendekatan ergonomi makro," in Prosiding Seminar Nasional Sains dan Teknologi ke-2, 2011, pp. 12-17.

[2] H. W. Hendrick and B. M. Kleiner, Macroergonomics : an introduction to work system design. Santa Monica: HFES Publisher, 2001.

[3] W. A. M. Sari, B. Suhardi, dan I. W. Suletra, "Pengaruh kondisi sistem kerja terhadap stress kerja dengan menggunakan macroergonomic organizational questionnare survey (MOQS)," J. Intech, vol. 7, no. 1, pp. 30-38, 2021.

[4] T. W. Tumewu dan R. A. Rachmadi, "Analisis karakter organisasi tenaga kependidikan UNIKA De La Salle Manado menggunakan macroergonomic organizational questionaire survey," J. SAINTEK, vol. 4, no. 1, pp. 1-7, 2020.

[5] M. M. Tambunan, D. Wahyuni, dan J. Kristanto, "Perancangan fasilitas kerja di bagian produksi PT .XYZ dengan menggunakan macroergonomic analysis and design (MEAD)," J. Sist. Tek. Ind., vol. 18 , no. 1, pp. 1-5, 2016.

[6] K. Hariyanto dan A. Hindratmo, "Identifikasi sistem kerja dalam mengurangi muskuloskeletal dan risiko cedera pada proses manufaktur (Studi kasus pelatihan mesin bubut mahasiswa teknik Universitas Wijaya Putra Surabaya)," J. SENOPATI, vol. 2, no. 1, pp. 33-42, 2020.

[7] M. C. Zulfa, M. Syahri, and D. R. L, "Desain fasilitas kerja alat penekuk akrilik menggunakan metode macroergonomic analysis and design (MEAD) pada CV. Caesar Advertising," in Prosiding SENASTIK, 2016, pp. 34-39.

[8] A. Haripurna and H. Purnomo, "Desain perancangan alat penyaring dalam proses pembuatan tahu dengan metode macro ergonomic analysis and design (MEAD)," J. Ilm. Tek. Ind., vol. 16, no. 1, pp. 22-27, 2017.

[9] A. H. Pradini, D. Rachmawati, and G. Madyono, "Perbaikan sistem kerja dengan pendekatan macroergonomic analysis and design (MEAD) untuk meningkatkan produktifitas pekerja (Studi kasus di UD Majid Jaya, Sarang, Rembang, Jawa Tengah)," Jurnal OPSI, vol. 12, no. 1, pp. 36-47, 2019.

[10] D. Rachmawati, dan T. Wibawa, "Evaluasi Sistem Kerja Di Industri Kerajinan Batik Kayu Sanggar Arjuna Desa Krebet Pajangan Bantul Dengan Pendekatan Macroergonomic Analysis And Design," Jurnal OPSI, Vol. 9, no. 2, pp. 79-84, 2016.

11] I. Mindhayani and H. Purnomo, "Perbaikan sistem kerja untuk meningkatkan produktivitas karyawan,” J. PASTI, vol. 10, no. 1, pp. 98-107, 2016.

[12] M. Tangahu, H. Purnomo, dan A. Mansur, "Desain sistem kerja mesin pemipih jagung yang ergonomi untuk meningkatkan produktivitas," J. Prozima, vol. 1, no. 2, pp. 90-98, 2017.

[13] G. M. Ayu, I. H. Nasution, dan I. Nazlina, "Peningkatan kualitas layanan kereta api sribilah dengan pendekatan macroergonomics analysis and design," e-Jurnal Tek. Ind. FT USU, vol. 3, no. 2, pp. 812, 2013.

[14] T. Ristyowati dan T. Wibawa, "Perancangan sistem kerja melalui pendekatan macroergonomic analysis and design," J. OPSI, vol. 11, no. 2, pp. 125-133, 2018.

[15] T. Aprianto dan H. Purnomo, "Desain pencetak dan pengepres tahu pada ukm tahu menggunakan metode macroergonomic analysis and design (MEAD)," in Seminar Nasiona; IENACO, 2014, pp. $22-28$. 